\title{
Schott Wants to be Climate Neutral by 2030
}

\author{
The company Schott is preparing to face up to the challenges of climate change. "We want \\ to turn Schott into a climate neutral company by 2030 and thus actively contribute to climate \\ protection," says Dr. Frank Heinricht, Chairman of the Board of Management. The 'Zero \\ Carbon' project is an integral part of the new Group Strategy.
}

With the 'Zero Carbon' strategy project, Schott enters a new era in its environmental and climate management. As a specialty glass manufacturer, the company operates in an energy-intensive industrial sector. Specialty glasses and glass-ceramics are melted in large melting tanks at temperatures of up to $1,700{ }^{\circ} \mathrm{C}$. In the past, these melting tanks have been heated with the fossil fuels natural gas, heating oil or electricity. A lot of energy is also required for the further processing of the glasses. Due to this energy requirement, the climate-relevant footprint is around one million tons of $\mathrm{CO}_{2} \mathrm{e}$ ( $\mathrm{CO}_{2}$ equivalents) per year.

"We see three steps in our commitment to climate protection: first, we want to avoid as many climate-damaging emissions as possible, significantly reduce unavoidable emissions in the next step and, if nothing else is possible, finally compensate for the remaining emissions," says Dr. Heinricht. The company is thus working towards helping to achieve the goals of the Paris Agreement on Climate Protection.

The action plan on achieving climate neutrality comprises four fields of action:

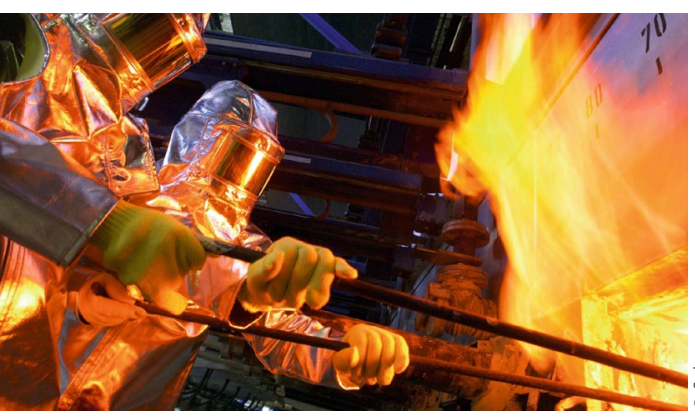

The production of specialty glasses is energyintensive: they are melted at temperatures of up to $1,700^{\circ} \mathrm{C}$.
- Improvement of energy efficiency

- Switching to green electricity

- Technological change

- Compensation for technologically unavoidable emissions

The company has been striving to improve its energy efficiency for decades. The introduction of oxy-fuel melting technology and the increasing use of electricity to heat the melting tanks since the 1990s has already made it possible to reduce specific energy consumption by more than $30 \%$. As part of the company's energy management system, experts are working intensively to identify and exploit further savings potential.

\section{Switching to green electricity by 2021}

When it comes to electrical power, Schott will be relying solely on green electricity in the future. The company intends to cover $100 \%$ of its electricity needs with renewable energy sources such as hydroelectric power, wind power and solar energy by 2021 . Here it is important that the green electricity has a high-quality certification and thus makes a contribution to the transition in energy.

\section{New technologies with a focus on hydrogen}

In the long term, the company intends to completely dispense with the use of fossil fuels, as far as this is technologically feasible. "This transformation process will take time and require high development and investment costs," says Heinricht. The company views hydrogen technology as a promising solution. In addition, researchers and melt- ing technologists are assessing the feasibility of other technological approaches. "We believe that as an innovation driver in our industry we can provide important impulses in this area in the coming years and decades," Dr. Heinricht concludes.

\section{Compensation for technologically unavoidable emissions}

Until $\mathrm{CO}_{2}$-free solutions for heating large glass melting tanks become available, Schott intends to compensate for technologically unavoidable emissions by investing in climate protection projects. The group is currently creating a compensation portfolio that meets high standards for the sustainability of the projects. These could, for example, include reforestation projects in various countries that are certified according to strict standards.

To calculate its climate-relevant emissions, Schott considers the emission of all greenhouse gases. The company currently includes emissions from its own production (Scope 1 of the Greenhouse Gas Protocol) and from energy purchased (Scope 2) in the calculation. In Scope 3, the company also takes business trips and employee commuting into account. In the medium term, the other Scope 3 emissions are then to be included, which also consider emissions in the supply chain. In order to establish comparability with regard to their climate impact, greenhouse gas emissions are expressed in $\mathrm{CO}_{2}$ equivalents $\left(\mathrm{CO}_{2} \mathrm{e}\right)$

Contact:

Schott AG, Mainz, Germany, www.schott.com/english 